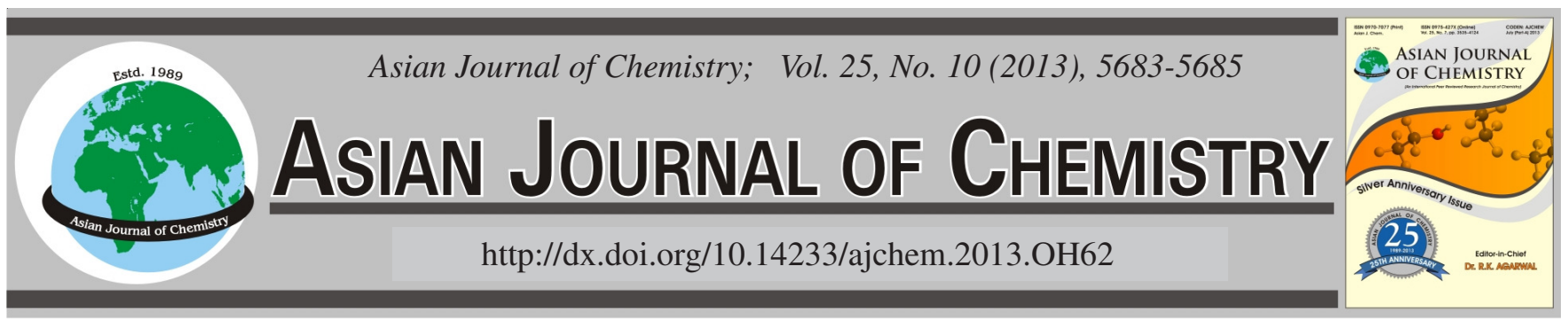

\title{
Synthesis and Characterization of Flame-Retardant Polyurethane Elastomers Using Phosphorus-Containing Chain Extender $\dagger$
}

\author{
Wenzong Xu*, WenXiu Li, Mingyuan Ren and Jianguo Yin
}

School of Materials Science and Chemical Engineering, Anhui University of Architecture, 856 Jinzai Road, Hefei 230022, Anhui Province, P.R. China

*Corresponding author: E-mail: wenzongxu@ sohu.com

\begin{abstract}
Phenylphosphonic diamine was synthesized from phenylphosphonic dichloride and characterized by Fourier transform infrared spectroscopy and nuclear magnetic resonance. Then phenylphosphonic diamine was used to prepare a series of phosphorus containing polyurethane elastomers (PPUEs) with different phosphorus contents. Combustion behaviour and thermal degradation behaviour of the PPUEs and polyurethane elastomer (PUE) were investigated by macroscale combustion calorimetry and thermogravimetric analysis. The macroscale combustion calorimetry result reveals that the value of peak heat release rate and total heat release of PPUEs are lower than those of PUE made by 3,3'-dichloro-4,4'-diaminodiphenylmethane (MOCA). The TGA result shows that PPUE2 has poorer thermal stability than PUE when they are obtained from the same soft segment, but the char yield of PPUE2 is higher than that of PUE.
\end{abstract}

Key Words: Phosphorus-containing diamine, Polyurethane, Flame retardancy, Thermal stability.

\section{INTRODUCTION}

Phosphorus is an effective element for imparting good fire resistance to polyurethanes (PUs) $)^{1-4}$. Compounds containing phosphorus are an important group of environmental friendly flame retardants which have several advantages such as low toxicity, no release of poison gas, e.g., dioxin or halogen acids during combustion, as well as low smoke production during burning. Generally, modifications of flame retardant polyurethane can be roughly grouped into two categories i.e., physical modifications and chemical modifications.

The physical modification approach provides a simple means of flame retardation, but polyurethane materials containing nonchemical bonding phosphorus are limited in several areas and the loss of phosphorus compounds is continuous during storage and processing. Thus, a better approach may be the incorporation of phosphorus into polyurethane materials in which phosphorus-containing structures are an integral part of the polyurethane molecule $e^{5-8}$.

In this paper, we report the synthesis and characterization of a phosphorus-containing chain extender phenylphosphonic diamine and a series of phosphorus containing polyurethane elastomer (PPUEs) synthesized by adjusting the soft segment. The structures and properties of PPUEs were studied by FTIR, TGA and macroscale combustion calorimetry.

\section{EXPERIMENTAL}

Polyester diol $\left(M_{n}=1213,1975,2600\right)$ was obtained from Shandong Xinhuarun Chemical Co. Ltd., 3,3'-dichloro-4,4'diaminodiphenylmethane (MOCA) was purchased from Zhangjiagang Daily Chemical Co. Ltd.

Synthesis of phenylphosphonic diamine: In a fournecked reactor $80 \mathrm{~g}$ phenyl phosphonic dichloride was added dropwise to $210 \mathrm{~g}$ ammonia under constant stirring at $0{ }^{\circ} \mathrm{C}$. A constant flow of nitrogen gas was maintained to remove the $\mathrm{HCl}$ produced. The reaction solution was maintained at $5-10{ }^{\circ} \mathrm{C}$ for $6 \mathrm{~h}$ to complete the reaction. The crude product was separated from the reaction mixture by filtration. Finally the product was recrystallized from absolute ethanol.

Synthesis of phosphorus-containing polyurethane elastomers: A certain amount of molten phenylphosphonic diamine or MOCA was added to stir prepolymer and the mixture was put in a Teflon mould and heated at $75^{\circ} \mathrm{C}$ for $2 \mathrm{~h}$ and $115^{\circ} \mathrm{C}$ for another $4 \mathrm{~h}$. Table- 1 gives a description of PPUEs and PUE.

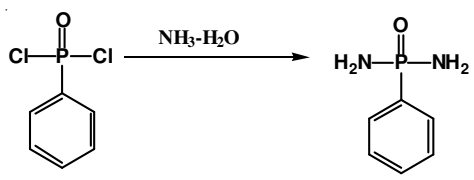

Scheme-I: Synthesis scheme of phenylphosphonic diamine

†Presented to the 6th China-Korea International Conference on Multi-functional Materials and Application, 22-24 November 2012, Daejeon, Korea 
TABLE-1

DESCRIPTION OF PPUEs AND PUE

$\begin{array}{cccccc}\text { Sample } & \text { Soft segment } & \mathrm{R}^{*} & \text { Chain extension coefficient* } & \text { Chain extender } & \text { P/Cl content wt. }(\%) \\ \text { PUE } & \text { Polyester diol 1975 } & 2 & 0.9 & \text { MOCA } & 2.5 \\ \text { PPUE1 } & \text { Polyester diol 1213 } & 2 & 0.9 & \text { PPDA } & 1.64 \\ \text { PPUE2 } & \text { Polyester diol 1975 } & 2 & 0.9 & \text { PPDA } & 1.33 \\ \text { PPUE3 } & \text { Polyester diol 2600 } & 2 & 0.9 & \text { PPDA } & 0.90\end{array}$

*R is the molar ratio of NCO of TDI and OH of soft segment; *Chain extension coefficient is the molar ratio of NH2 of chain extender and NCO of prepolymer

Infrared data were obtained with a Spectrum100 FTIR Spectrometer (Perkin Elmer). ${ }^{1} \mathrm{H}$ NMR and ${ }^{31} \mathrm{P}$ NMR spectra were obtained with a Bruker AV400. TGA of the samples were carried out using a NETZSCH STA 409PC/PG.MCC-2 was used to investigate the combustion of the PPUEs.

\section{RESULTS AND DISCUSSION}

Fig. 1 shows the FTIR of phenylphosphonic diamine and PPDC. In phenylphosphonic diamine, the typical amino group stretching absorptions at $3351,3222 \mathrm{~cm}^{-1}$ from N-H asymmetric and symmetric stretching are found. $1442 \mathrm{~cm}^{-1}$ from $\mathrm{P}-\mathrm{Ph}$ stretching vibration is also found. The absorption peaks at 550 $\mathrm{cm}^{-1}$ from $\mathrm{P}-\mathrm{Cl}$ are found in PPDC and disappear in phenylphosphonic diamine.

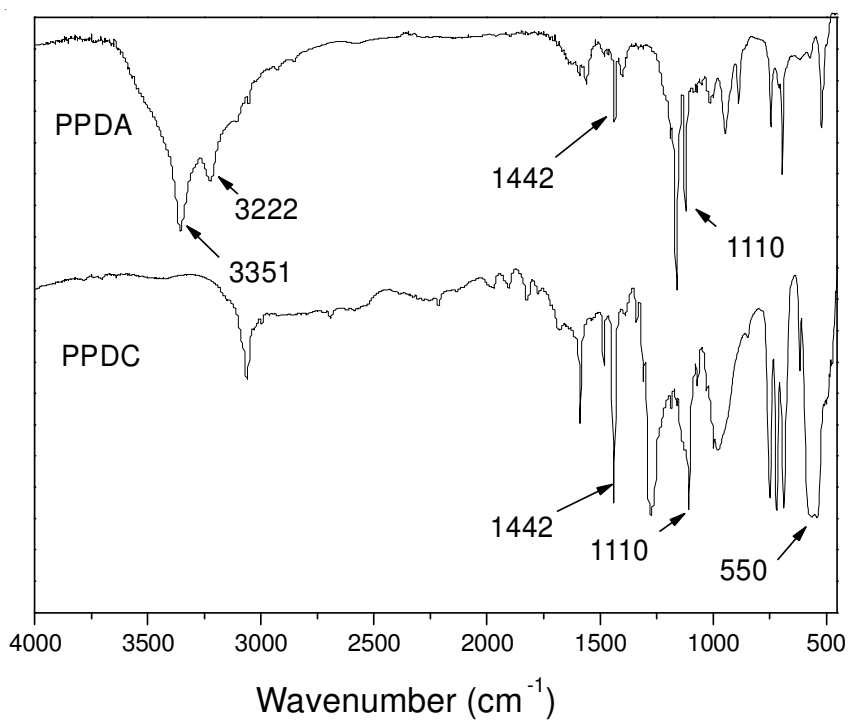

Fig. 1. FTIR of phenylphosphonic diamine and PPDC

The ${ }^{1} \mathrm{H}$ NMR and ${ }^{31} \mathrm{P}$ NMR spectra of phenylphosphonic diamine are shown in Figs. 2 and 3. The ${ }^{1} \mathrm{H}$ NMR spectrum exhibits the corresponding proton signals at 3.8-4.2 ppm due to the $-\mathrm{NH}_{2}$, at 7.35-7.81 ppm due to the aromatic protons and the hydrogen peaks from $\mathrm{H}_{3}$ are the lowest due to the proton-donating effect of $\mathrm{P}=\mathrm{O}$. The peak integration results closely correspond to the ratios of the specific protons of phenylphosphonic diamine. ${ }^{31} \mathrm{P}$ NMR spectrum shows a sharp single peak, which indicates high purity of phenylphosphonic diamine.

Thermal property of PPUEs: Thermal stability properties of PUE and PPUEs were evaluated using TGA in nitrogen atmosphere. The TGA curves and the characteristic thermal decomposition temperature of PUE and PPUEs are shown in Fig. 4 and Table-2. $\mathrm{T}_{5}, \mathrm{~T}_{50}$ and $\mathrm{T}_{\max }$ are the temperature of $5 \%$, $50 \%$ and max mass loss of the sample.

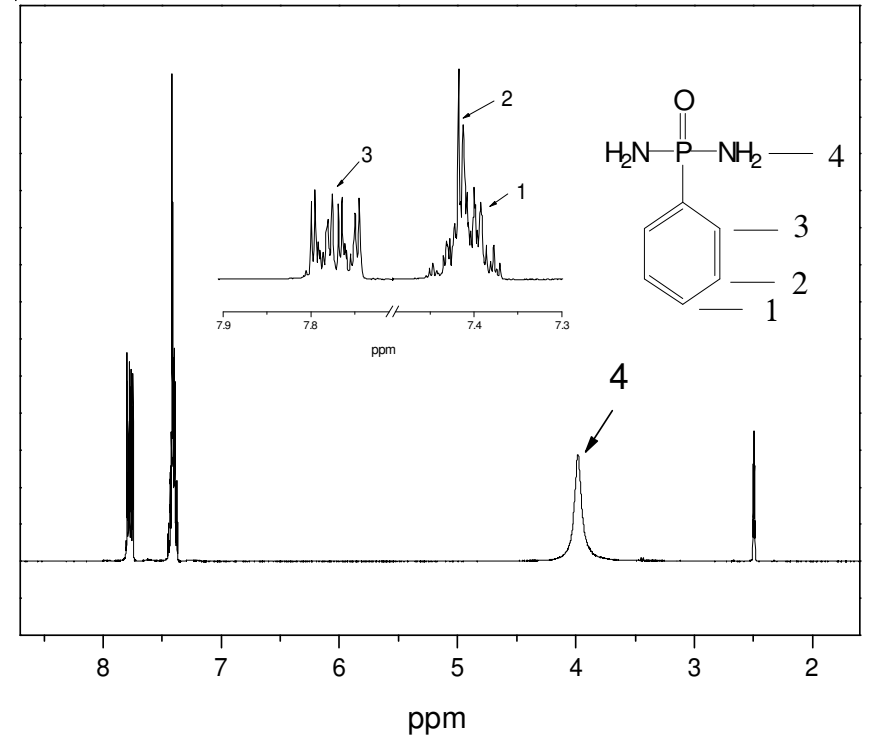

Fig. $2 .{ }^{1} \mathrm{H}$ NMR spectrum of phenylphosphonic diamine

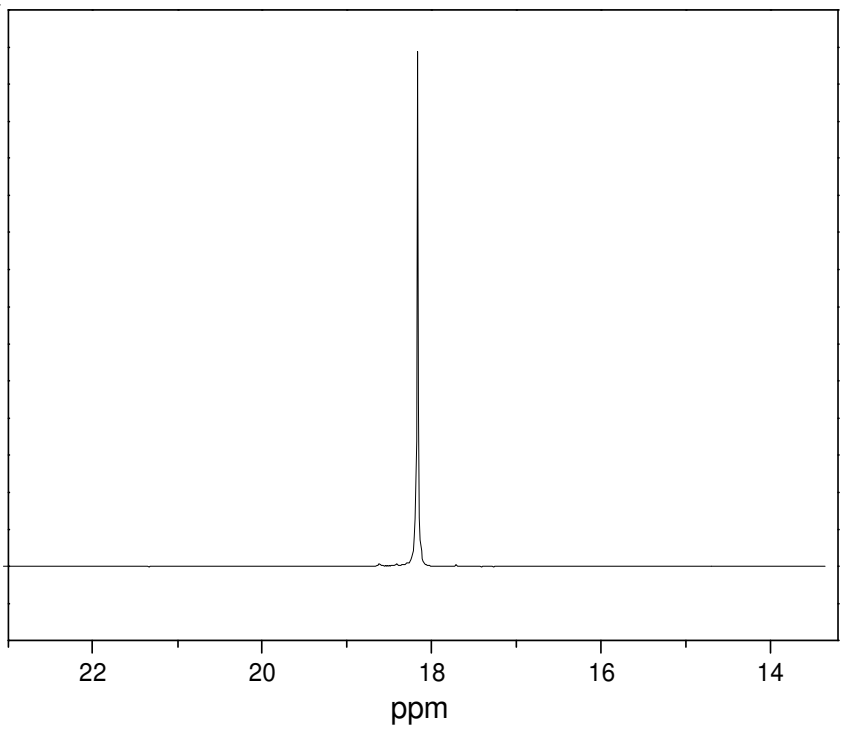

Fig. 3. ${ }^{31} \mathrm{P}$ NMR spectrum of phenylphosphonic diamine

The $\mathrm{T}_{5}, \mathrm{~T}_{50}$ and $\mathrm{T}_{\max }$ of PPUE- 1 are 252.1, 414.6 and 411.2 ${ }^{\circ} \mathrm{C}$ respectively,and these are the lowest in all PPUEs. It can be concluded that PPUE1 has a poor thermal stability. The possible reason is that the molecular weight of PPUE1 soft segment is the lowest among the three PPUEs. In other words, PPUE1 has the highest hard segment content. As a result, more poor thermal stability biuret is created in PPUE1. However, the char yield of PPUE1 is the highest in all PPUEs and this is attributed to the fact that phosphorus promotes carbonization. Comparing PPUE2 with PUE, the $\mathrm{T}_{5}$ of PPUE2 is lower than 


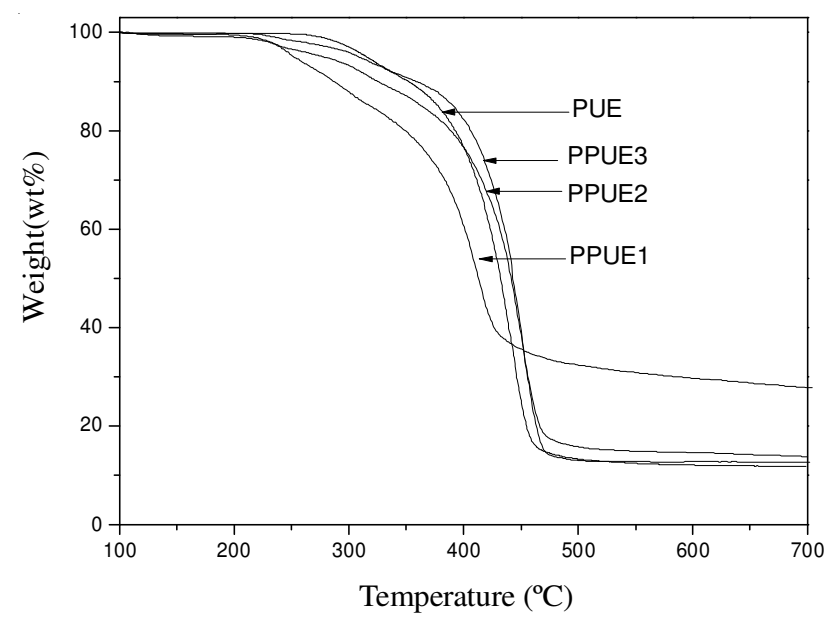

Fig. 4. TG of PPUEs and PUE

\begin{tabular}{ccccc}
\multicolumn{5}{c}{ TABLE-2 } \\
TG DATA OF PPUEs AND PUE \\
\hline Sample & $\mathrm{T}_{5}\left({ }^{\circ} \mathrm{C}\right)$ & $\mathrm{T}_{50}\left({ }^{\circ} \mathrm{C}\right)$ & $\mathrm{T}_{\max }\left({ }^{\circ} \mathrm{C}\right)$ & Char yield $(\%)$ \\
\hline PUE & 315.6 & 432.3 & 441.7 & 11.8 \\
PPUE1 & 252.1 & 414.6 & 411.2 & 27.1 \\
PPUE2 & 279.0 & 441.5 & 449.6 & 13.7 \\
PPUE3 & 308.9 & 443.0 & 450.7 & 12.6 \\
\hline
\end{tabular}

that of PUE. The possible reason is that the thermal stability of phosphorus-containing groups is poor. But the $\mathrm{T}_{\max }$ and the char yield of PPUE2 are all higher than those of PUE.

Flame retardant property of PPUEs: Macroscale combustion calorimetry is a pyrolysis combustion flow calorimeter and the heat release rate recorded by macroscale combustion calorimetry is calculated from the measured oxygen consumption rate. Macroscale combustion calorimetry test provides a convenient methodology for estimating the fire hazard potential of a material using only milligram samples.

Fig. 5 and Table- 3 show the plots and data of PPUEs and PUE obtained from macroscale combustion calorimetry . As can be seen, the PHRR and THR of the PPUEs decrease while the phosphorus content increase. From PPUE3 to PPUE1, the PHRR and THR decrease from $368.6 \mathrm{~W} / \mathrm{g}$ and $15.2 \mathrm{KJ} / \mathrm{g}$ to $233.7 \mathrm{~W} / \mathrm{g}$ and $14.1 \mathrm{KJ} / \mathrm{g}$, respectively. The possible reasons for this may include the following: phosphorus is an efficient flame-retardant element. After the sample is ignited, phosphorus compounds form ammonium polyphosphate during combustion, promote the formation of a protective char and the char can protect the underlying materials from further burning and reduce its heat release, which results in enhanced retardancy. Comparing PPUE1 with PUE, the PHRR and THR of the PPUE1 are lower than those of PUE. It is believed that the phosphorus element is responsible for the decreased heat release rate.

The ignition temperature corresponds to the temperature of the maximum heat release rate. The ignition temperature for PPUE2 is higher than that for PUE. This means that PPUE2 delays the time of reaching the maximum flammable gas release rate.

\section{Conclusion}

FTIR, ${ }^{1} \mathrm{H}$ NMR and ${ }^{31} \mathrm{P}$ NMR were used to analyze an organophosphorus compound, phenylphosphonic diamine, which was synthesized by the reaction of PPDC and ammonia

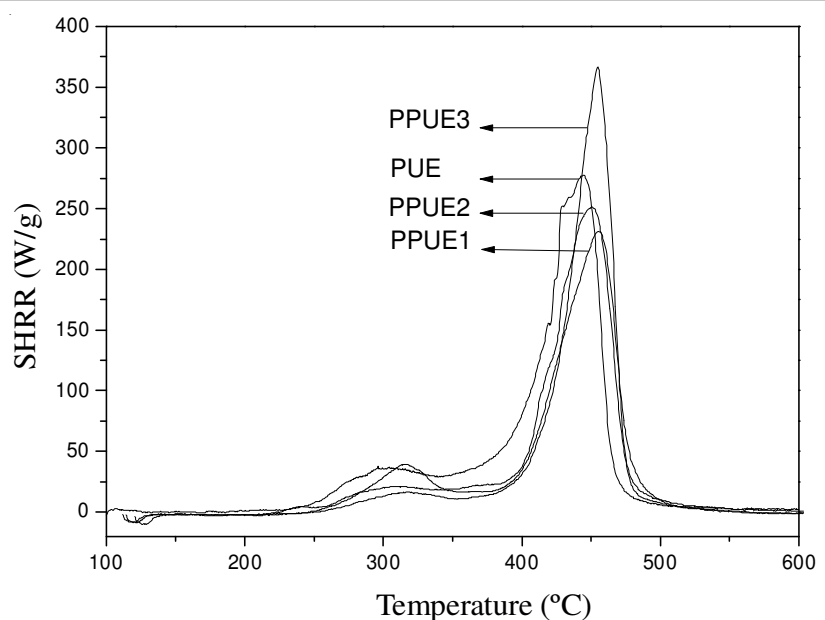

Fig. 5. Specific heat release rate curves of the PUE and PPUEs

\begin{tabular}{cccc}
\multicolumn{4}{c}{ TABLE-3 } \\
RESULTS OF MCC OF PUE AND PPUEs \\
\hline Samples & PHRR $(\mathrm{W} / \mathrm{g})$ & THR $(\mathrm{KJ} / \mathrm{g})$ & $\mathrm{T}_{\mathrm{p}}\left({ }^{\circ} \mathrm{C}\right)$ \\
\hline PUE & 278.4 & 18.0 & 444.6 \\
PPUE1 & 233.7 & 14.1 & 455.7 \\
PPUE2 & 252.0 & 15.0 & 451.0 \\
PPUE3 & 368.6 & 15.2 & 454.9 \\
\hline
\end{tabular}

water. The results demonstrate a successful synthesis of novel phosphonic amide. Phosphorus-containing polyurethane elastomers were synthesized by two-step polymerization based on phenylphosphonic diamine. The TGA results indicate that the thermal stability of phosphorus-containing polyurethanes is lower than that of common polyurethane. However, the incorporation of phenylphosphonic diamine into polyurethane increases the char yield and a glass coating and a protective carbonized skin may be formed on the pyrolyzing phosphoruscontaining polyurethanes, thus possibly leading to fire protection. The flame retardant properties of PPUEs and PUE were evaluated by macroscale combustion calorimetry experiments. The PHRR and THR of FPUE-2 are $252.0 \mathrm{~W} / \mathrm{g}$ and $15 \mathrm{KJ} / \mathrm{g}$. The results show PPUE-2's better flame retardancy than that of PUE.

\section{ACKNOWLEDGEMENTS}

The authors thank the National Natural Science Foundation of China (No. 21004001/B040601) and the Science and Technology Agency of Anhui Province (No. 0902023064) for their financial support.

\section{REFERENCES}

1. D. Price, L.K. Cunliffe, K.J. Bullett, T.R. Hull, G.J. Milnes, J.R. Ebdon, B.J. Hunt and P. Joseph, Polym. Degrad. Stab., 92, 1101 (2007).

2. T.L. Wang, Y.L. Cho and P.L. Kuo, J. Appl. Polym. Sci., 82, 343 (2001).

3. Y.H. Chao and J.H. Wang, J. Fire Sci., 19, 137 (2001).

4. F.T. Lee, J. Green and R.D. Gibilisco, J. Fire Sci., 2, 439 (1984).

5. T.C. Chang, Y.S. Chiu, H.B. Chen and S.Y. Ho, Polym. Degrad. Stab., 47, 375 (1995).

6. Y.A. Pinto, L.L.Y. Visconte and J. Gallo, Polym. Degrad. Stab., 69, 257 (2000)

7. Z.L. Ma, W.G. Zhao, Y.F. Liu and J.R. Shi, J. Appl. Polym. Sci., 66, 471 (1997).

8. C.H. Shao, J.J. Huang, G.N. Chen, J.-T. Yeh and K.-N. Chen, Polym. Degrad. Stab., 65, 359 (1999). 